\title{
Schistosoma mansoni Polo-like kinases and their function in control of mitosis and parasite reproduction
}

\author{
COLETTE DISSOUS ${ }^{1}$, CHRISTOPH G. GREVELDING ${ }^{2}$ and THAVY LONG ${ }^{1}$ \\ ${ }^{1}$ Center for Infection and Immunity of Lille Inserm U1019 - CNRS UMR 8204, University Lille Nord de France, \\ Institut Pasteur de Lille, 59019 Lille Cedex, France \\ ${ }^{2}$ Institute for Parasitology, Justus-Liebig-University, 35392 Giessen, Germany
}

Manuscript received on December 21, 2010; accepted for publication on March 14, 2011

\begin{abstract}
Polo-like kinases are important regulators of cell cycle progression and mitosis. They constitute a family of conserved serine/threonine kinases which are highly related in their catalytic domains and contain polo boxes involved in protein-protein interactions and subcellular localization. In mammals, five Plks (Plk 1-5) encompass diverse roles in centrosome dynamics, spindle formation, intra S-phase and G2/M checkpoints and DNA damage response. Plk1 is a key positive regulator of mitosis and is overexpressed in various types of cancers. Plk4 is a divergent member of the Plk family, with essential functions in centriole duplication. Homozygous disruption of Plk1 or Plk4 in mice is lethal in embryos. Two Plk members SmPlk1 and SmSak, homologous to Plk1 and Plk4 respectively, are present in the parasitic platyhelminth Schistosoma mansoni. Structural and functional analyses of SmPlk1 have demonstrated its conserved function in the regulation of cell cycle G2/M transition in Xenopus oocytes. The anti-cancer drug BI 2536 (the most potent and selective Plk1 inhibitor) inhibits specifically the catalytic activity of SmPlk1 and induced profound alterations in schistosome gonads, indicating a role of SmPlk1 in parasite gametogenesis and its potential as a novel chemotherapeutic target against schistosomiasis. Functions of SmSak in cell cycle regulation and schistosome gonad development are currently investigated.
\end{abstract}

Key words: cell cycle, Polo-like kinases, reproduction, Schistosoma mansoni.

\section{SCHISTOSOME BIOLOGY AND PROTEIN KINASES}

Schistosomiasis is a water-borne disease and one of the most important parasitic diseases worldwide, with more than 200 million people infected. Transmission of schistosomes is endemic in over 70 tropical and subtropical countries. Control of schistosomiasis relies in priority on mass treatment of human populations with Praziquantel (PZQ), a drug which has been proven for decades to be efficient to reduce morbidity and mortality due to schistosomiasis. However, its widespread use and its inefficacy on juvenile parasites raise fears that schistosomes will develop resistance to PZQ, and there is an urgent need to

Correspondence to: Colette Dissous

E-mail: colette.dissous@pasteur-lille.fr find alternative drugs and novel concepts to fight schistosomes (Doenhoff et al. 2008).

Mating and sexual maturation of adult male and female worms of $S$. mansoni in the human host lead to the production of numerous eggs which are responsible for transmission, but also for the pathology of schistosomiasis. Eggs are eliminated in faeces, and they assure parasite transmission through the infection of fresh water molluscs as intermediate hosts. Aside, a large proportion of eggs become trapped into human tissues, and granulomas formed around these eggs have serious pathogenic consequences (Ross et al. 2002). In this context, any strategy that aims to reduce worm fecundity and schistosome reproduction represents a valuable concept to combat schistosomiasis. 
A unique feature of schistosome biology is that sexual maturation of the female is strictly dependent on the male. Worm pairing induces the development of female reproductive organs, ovary and vitellarium. This sexual maturation has been shown to be dependent on sustained mitotic activities and cell differentiation, and of signalling processes implying conserved molecules and networks. The structural and functional characterization of diverse receptor and cytosolic tyrosine kinases expressed in parasite gonads has largely demonstrated the central role played by tyrosine kinase signalling in cell differentiation and maturation of parasite ovaries (for review Beckmann et al. 2010a, Dissous and Grevelding 2011). Recently, Long et al. (2010) have studied the importance of cell cycle kinases such as Plks in schistosome development and parasite reproduction.

\section{THE POLO-LIKE KINASE FAMILY}

Polo-like kinases (Plks) constitute a family of serine/ threonine kinases (Ser/Thr) with crucial and conserved cellular functions in all eukaryotes. They are important regulators of the cell cycle progression during M-phase, primarily involved in the assembly and dynamics of the mitotic spindle apparatus and in the regulation of the activation of cyclin-dependent protein kinases (Cdks) (Glover et al. 1998, Nigg 1998). Mutations causing mitotic and meiotic defects were at the origin of the discovery of the first polo gene in Drosophila melanogaster, a gene further found to encode in all organisms a highly conserved kinase (Sunkel and Glover 1988). Budding yeast (Saccharomyces cerevisiae) and fission yeast (Schizosaccharomyces pombe) each have a single Plk (Cdc5 and Plo1, respectively) that regulates all the steps of cell division: mitotic entry, mitotic exit and cytokinesis (Kitada et al. 1993, Ohkura et al. 1995). However, multicellular organisms generally possess several Plks, which can have different functions (Archambault and Glover 2009). Plks have a common structure composed of a conserved amino-terminal Ser/Thr kinase domain and a carboxy-terminal Polo-box domain (PBD) that coordinates their interaction with target proteins and their subcellular localization. In vertebrates, there are four well-known Plks (Plk1-4). Plk1-2-3 have similar structures, and each of their PBDs contain two conserved polo boxes that can dimerise intramolecularly and form a pocket for binding to phosphoserine and phosphothreonine motifs (inside the Ser-pSer/pThr-Pro$\mathrm{X}$ sequence). Polo box dimerization and binding to the phospho-motif induce conformational changes and kinase activation by the release of a catalytic domain accessible to the substrate (Elia et al. $2003 \mathrm{a}$, b) (Fig. 1).

Plk1 is the best characterized member of the Plk family, and is homologous to the Drosophila kinase Polo. Primarily expressed during late G2 and M phases, Plk1 is a key regulator of mitosis, meiosis and cytokinesis (Archambault and Glover 2009, Lowery et al. 2005), and its dramatic over-expression in proliferating cells including many cancers has already promoted human Plk1 to a validated target for anti-cancer therapy (Steegmaier et al. 2007, Schöffski 2009). Whereas the functions of Plk1 in cell division are well established, the roles of Plk2 and Plk3 are less well understood. Plk2 (serum-inducible kinase, Snk) and Plk3 (FGF-inducible kinase, Fnk or Prk) are early-response genes activated in quiescent cells following serum stimulation, and they are involved in checkpoint-mediated cell cycle arrest. Plk2 participates in S-phase arrest and is a direct target for transcriptional regulation by p53 (Matthew et al. 2007). Plk3 is considered to be a tumor suppressor and is activated in response to DNA damage. It contributes to cell cycle arrest and apoptosis, probably by several mechanisms, including a p53-dependent pathway (Xie et al. 2001).

Plk4 (also named Sak for Snk/Plk-akin kinase) is a divergent and unique member of the Plk family that shares little homology with Plk1, Plk2 and Plk3. It contains only one of the two bipartite polo-box motifs, suggesting that its regulation and substrate repertoire are different from those of other Plks (Lowery et al. 2005). Plk4 has a predominant function in centriole duplication, but the recent discovery that Plk4 is implied in cytokinetic exit broadens the role of this kinase in centrosome maturation and mitotic progression (BettencourtDias et al. 2005). Its turn-over must be strictly controlled, and this is achieved by an autoregulatory mechanism implying its autophosphorylation in PEST sequence for degradation by the proteasome (Silibourne and Bornens 2010).

Recently, a novel Plk5 kinase has been identified in vertebrates. Mouse Plk5 has been shown to be inducible 


\section{5 human PIks}
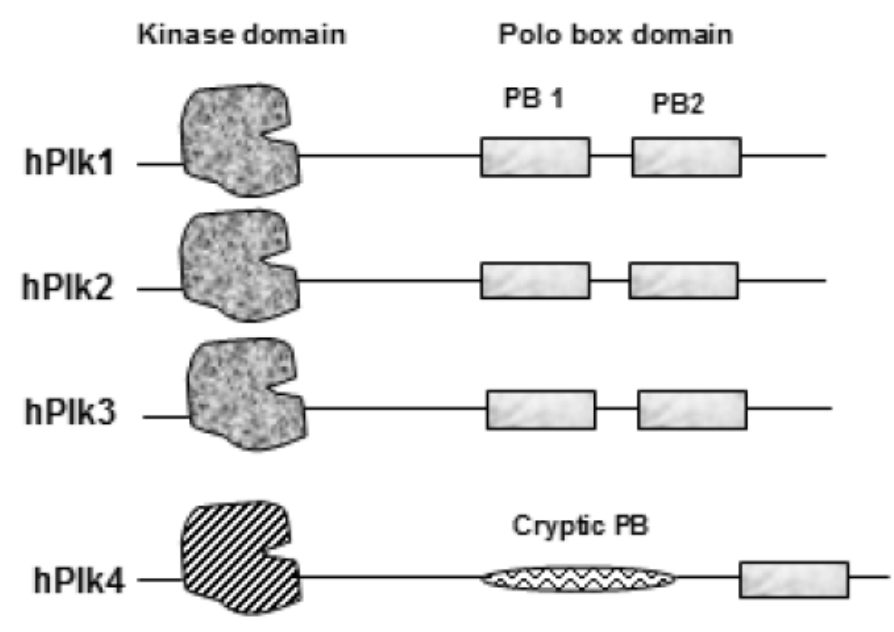

PB like

hPIk5

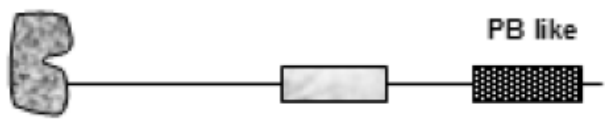

\section{S. mansoni PIks}

SmPIk1

\section{SmSak}

Fig. 1 - The polo-like kinase family. Schematic representation of the five identified polo-like kinases in human cells. hPlk1, hPlk2 and hPlk3 have similar structures, each composed of a Plk-conserved and specific Ser/Thr kinase domain in their N-terminal part and a polo-box domain formed by two conserved polo-boxes (PB1 and PB2) in their C-terminal part. hPlk4 is a divergent Plk (also named Sak) containing a less-conserved kinase domain and a polo-box domain composed of a cryptic polo-box and a single polo-box. hPlk5 has a structure similar to Plk1, 2 and 3 but the sequence of human Plk5 contains a stop codon that produces a truncated protein lacking the N-terminal half part of the kinase domain (Archambault and Glover 2009, Andrysik et al. 2010). In the genome of S. mansoni (Berriman et al. 2009), only two genes encoding respectively SmPlk1 and SmSak have been found (Long et al. 2010).

by stress as well as DNA damage, and it is localized in the nucleolus. Interestingly, the Plk5 gene in humans (as well as in great apes) contains a stop codon that disrupts the kinase domain and produces a truncated protein that still retains some Plk5 functions. The expression of human Plk5 is inducible in response to stress and the protein controls $\mathrm{G} 2 / \mathrm{M}$ checkpoint in response to DNA damage (Andrysik et al. 2010).

\section{THE $S$. mansoni POLO-LIKE KINASES}

The first Plk sequence identified in S. mansoni (GenBank No. AAV49163, sequence submitted by Vermeire et al.) was shown to encode a protein SmPlk1 homologous to the kinase Polo and Plk1 proteins (Long et al. 2010). SmPlk1 exhibited $43 \%$ of identity with Polo from D. melanogaster, the founding member of the Plk family, 49\% with the human Plk1 or with Plx1 from
Xenopus, and 34\% with Plc from Caenorhabditis elegans. Protein sequence analysis confirmed that SmPlk1 shared the common structure of Polo members composed of a highly conserved N-terminal kinase domain and a C-terminal polo-box domain (PBD) including two polo-boxes (Fig. 2). SmPlk1 exhibited 30\%, 31\% and $16 \%$ identity with human Plk2, Plk3 and Plk4 respectively. The kinase domain of SmPlk1 was shown to contain the typical subdomains of protein kinases. The consensus sequence H-R-D-L-K-X-X-N in subdomain VI and the typical motif G-T-P-N-Y-I-A-P-E in subdomain VIII were strong indicators for Ser/Thr kinase activity. SmPlk1 also contained within its activation loop the conserved threonine residue (T182) described as the major phosphorylation site in mitotic Plks and essential for Plk activation (Jang et al. 2002). The subdomain I of SmPlk1 contained as a part of the ATP binding site the GxGGFAxC motif specific for Plk proteins, in 


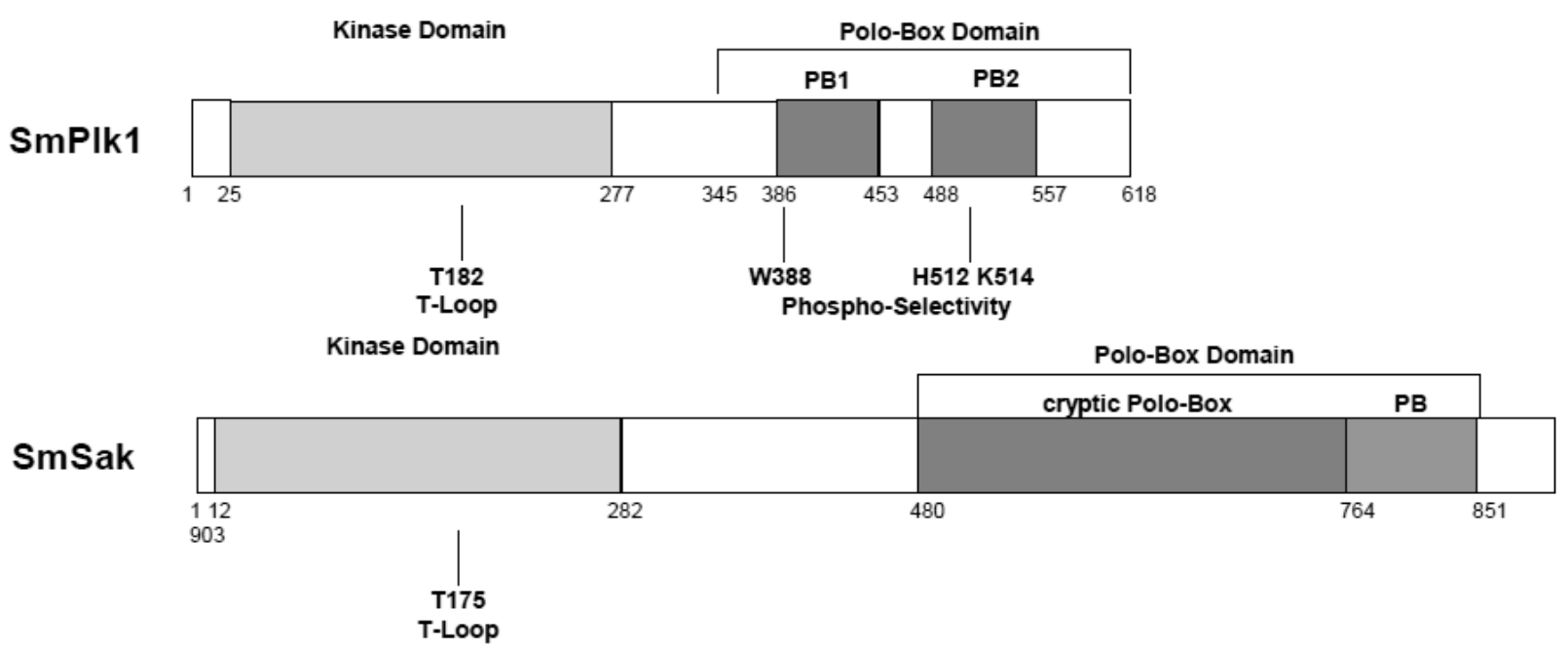

Fig. 2 - Schematic representation of the two S. mansoni polo-like kinases. SmPlk1 is similar to other Plk1 proteins composed of a conserved N-terminal kinase domain containing in its activation T-loop the conserved Threonine residue (T182) whose phosphorylation is required for activation, and in its C-terminal part a polo-box domain composed of two conserved polo-boxes (PB1 and PB2) containing the three amino-acids (W388, H512 and K514) involved in the binding to specific phosphosubstrates. SmSak is a second Plk of S.mansoni and similar to the divergent member of the Plk family, Plk4 also named Sak. Its kinase domain contains the phosphorylable T175 residue in the activation T-loop, and its $\mathrm{C}$-terminal part is characteristic of Plk4/Sak proteins formed by a single polo-box and a cryptic polo-box. Numbers indicate the position of amino acids in the protein sequences.

place of the canonical GxGxxGxV sequence found in all other protein kinases (Lane and Nigg 1997, Hanks and Quinn 1991). The C-terminal region of SmPlk1 formed by two conserved polo-boxes (PB1 and PB2) is connected to the kinase domain by a short, non-conserved linker and forms the complete PBD known to regulate subcellular localization of Plk1 during mitosis (Elia et al. 2003a). The three residues present in the PBD of human Plk1 and shown to be essential for specific binding to phosphosubstrates (Elia et al. 2003b) are perfectly conserved in SmPlk1 (residues W388, H512 and K514) (Fig. 2).

Screening of the Sanger S. mansoni genome database (Welcome Trust Sanger Institute web site) (Berriman et al. 2009) with the SmPlk1 cDNA sequence indicated that SmPlk1 was present in single copy in the parasite genome. In silico analyses showed that the SmPlkl gene was composed of seven exons of variable size ranging from 98 to $417 \mathrm{bp}$ extending over more than $5818 \mathrm{bp}$, the exact size of intron 5 being undetermined.

Further data mining of the complete nuclear genome of S. mansoni (Berriman et al. 2009) also indicated the existence of another gene encoding a Plk similar to Plk4/Sak proteins. The gene SmSak is composed of ten exons of variable sizes and extends over a total of 13000 bp. The SmSak cDNA sequence (GenBank No. GU 084154) was shown to encode a protein kinase homologous to Plk4 members and to be different from SmPlk1 with only $17 \%$ identity along the total sequence. With respect to its kinase domain, SmSak was more identical to Plk4 members than to SmPlk1, indicating that SmSak was a second schistosome Plk belonging to the group 4 of the Plk family. The analysis of the C-terminal domain of SmSak confirmed that the SmSak PBD contained a single polo box and the cryptic polo box (cry-pb) characteristic of Sak proteins (see Fig. 1), which was found upstream from the single polo box (Fig. 2).

No other Plk gene has been found in the genome of the schistosome, indicating that this helminth parasite would express only two Plks sufficient to govern and orchestrate the different steps of cell cycle progression and mitosis, whereas the helminth $C$. elegans possesses three Plks (Plc1, Plc2, Plc3) (Chase et al. 2000) 
as well as a structurally divergent zyg-1 kinase with Saklike functions in centriole duplication (O'Connell et al. 2001).

\section{CONSERVED MITOTIC FUNCTIONS OF SmPIk1}

Plk1 proteins are primarily expressed during late G2 and $M$ phases and regulate much of the machinery involved in mitosis in all animal species (Archambault and Glover 2009, Lowery et al. 2005). At the G2/M transition, Plk1 activates the dual-specificity phosphatase $\mathrm{Cdc} 25 \mathrm{C}$ that dephosphorylates the maturation promoting factor (MPF or Cdc2-cyclin B1 complex) promoting its activity and its translocation in the nucleus. In Xenopus laevis oocytes, evidence has been obtained that injection of mRNA encoding an active form of Plx1 was sufficient to initiate meiosis resumption in resting oocytes and to induce Germinal Vesical BreakDown (GVBD), a biological process easily seen by eye by the appearance of a white spot at the center of the animal pole of the oocyte (Qian et al. 1999). The Xenopus oocyte, a model previously shown to be suitable for the expression and the activity of diverse schistosome kinases (Vicogne et al. 2004, Yan et al. 2007, Beckmann et al. 2010b), has been used to analyse the role of SmPlk1 in mitosis (Long et al. 2010). The potential of SmPlk1 to trigger resumption of meiosis in Xenopus oocytes was shown by the injection of mRNA encoding a constitutively active mutant of SmPlk1, in which the conserved threonine residue (T182) whose phosphorylation is essential for Plk activation had been changed to aspartate in order to mimick its phosphorylation. SmPlk1T182D was able to phosphorylate Cdc25 and to induce, in Plx1-depleted oocytes, levels of GVBD similar to those obtained with normal oocytes using progesterone, the natural hormonal stimulus. Further data also showed that a dead kinase version of SmPlk1 (SmPlk1DK) completely inhibited GVBD induced by progesterone in normal oocytes, indicating that it could block as a negative dominant mutant the endogenous Plx1 activity during mitotic signalling. Very likely this inhibition was due to the conserved polo-box motifs present in the inactive kinase SmPlk1DK that assure its adequate subcellular localization, and as a consequence its competition with Plx1 for specific partners. In summary, these results have demonstrated the con- served function and activity of SmPlk1, which is able both to recognize the same partners as Plx1 in the oocyte and to undergo a conserved mechanism of activation requiring its phosphorylation of the residue T182 (Long et al. 2010). Recent data confirmed that such Plx1-like properties were addressed exclusively to SmPlk1 and not to SmSak, the second Plk found in S. mansoni (Long, unpublished). Work is currently in progress to define the specific role of SmSak in cell cycle progression and its possible implication in centrosome duplication and in other functions characteristic of Sak proteins (Bettencourt-Dias et al. 2005).

\section{SmPIk1 CONTROLS GAMETOGENESIS IN SCHISTOSOMES}

Schistosome Plks have been shown to be expressed with different intensities throughout the life cycle of $S$. mansoni with an abundance of SmPlk1 transcripts in sporocysts and in adult females, two parasite stages containing germinal cells with an elevated mitotic index. In situ hybridization experiments confirmed the presence of significant amounts of SmPlkl transcripts in the female vitellarium and ovary, but also in male testes. These data already indicated the importance of the SmPlk1 kinase in the reproductive organs of schistosomes and suggested that targeting its activity could affect gametogenesis and reproduction in schistosomes (Long et al. 2010).

Given the importance of Plks in cancer, diverse Plk inhibitors (namely ATP-site-directed molecules) now exist which are currently being evaluated in preclinical and clinical studies for their potential as treatments in oncology. Among these molecules, the dihydropteridinone BI 2536 is actually the most potent and advanced Plk-1 molecule in clinical development (Steegmaier et al. 2007, Schöffski 2009). Long et al. (2010) have shown that this drug had a remarkable effect on the parasite kinase SmPlk1, inhibiting totally the phosphorylating activity of the recombinant protein at nanomolar doses $(20 \mathrm{nM})$. At the opposite, no inhibitory effect of BI 2536 was observed on the kinase activity of recombinant SmSak, indicating that SmPlk1 and SmSak are two distinct kinases with potentially different substrates, partners and functions. This result also confirmed the high selectivity of the inhibitor BI 2536 for Plk1 proteins (Steegmaier et al. 2007). 


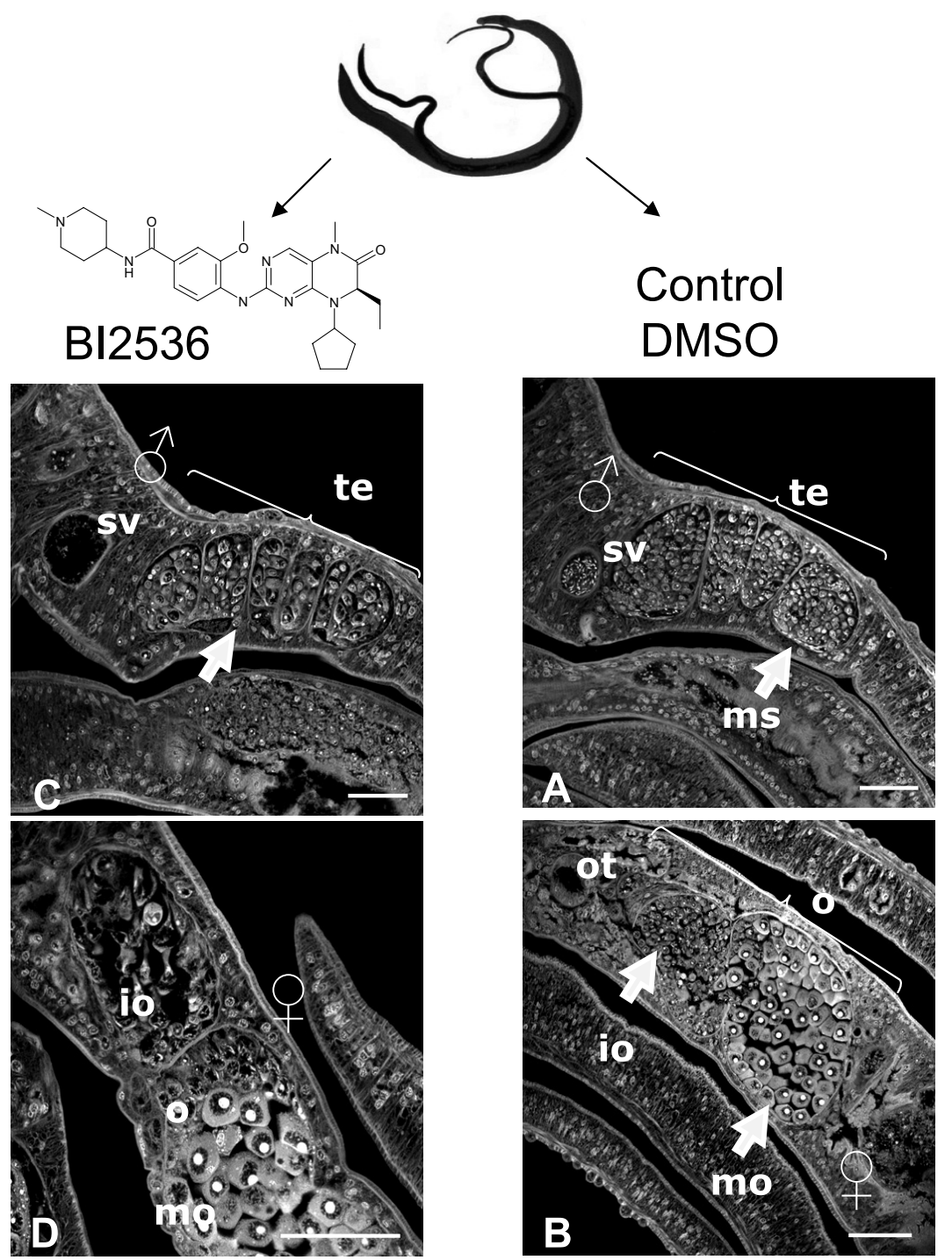

Fig. 3 - In vitro effect of BI 2536 on the morphology of schistosomes. Paired adult worms were cultured in vitro without or with BI 2536 $(100 \mathrm{nM})$ for 7 days, then examined by confocal laser scanning microscopy (Long et al. 2010). In untreated male parasites, testes (te) are full of spermatocytes, and the sperm vesicle (SV) is full of sperm. In untreated female worms, we can observe immature (io) and mature (mo) oocytes contained in the ovary as well as the ootype (ot). In male worms, BI 2536 induces a diminution of the production of spermatocytes in testes, and in the sperm vesicle no more sperm is detected. In treated-females, BI 2536 affects the production of oocytes. Immature oocytes are less numerous and exhibit important morphological changes. These results indicate that the drug affects gametogenesis both in male and female parasites.

In adult schistosomes cultured in vitro, BI 2536 was shown to induce dramatic alterations in testes and ovaries with significant effects on oogenesis and spermatogenesis, leading to a reduction of immature gametes such as oogonia and spermatogonia, and a diminution of fully-differentiated sperm (Fig. 3). These results confirmed the key role in schistosomes of SmPlk1 in cell cycle (and particularly in mitosis/meiosis), its im- portance in parasite reproductive activities, and thus its potential as a novel chemotherapeutical target for the control of schistosomiasis.

\section{CONCLUSIONS}

Schistosomes still represent a serious public health concern for human and animals causing major economical 
problems in endemic areas (Muhumuza et al. 2009, King 2010). Moreover, mass chemotherapy using only one drug Praziquantel has raised the fear that schistosomes become resistant to the drug and urges on researchers to discover alternative drugs.

Protein kinases control the majority of biological processes in normal as well as in cancer cells, and they are actually favorite targets for cancer therapy with a large battery of small-molecule kinase inhibitors already available for human pre-clinical or clinical uses. Convincing studies have demonstrated the importance of protein kinases in schistosome growth and development (Dissous et al. 2006, 2007, Knobloch et al. 2007, Beckmann et al. 2010a). The effect of anti-cancer drugs on the reproductive activity of parasites as well as on their survival in in vitro culture (shown recently for the Abl-kinase inhibitor Imatinib by Beckmann and Grevelding 2010) reinforces the hypothesis that parasite protein kinases could represent new targets for antischistosomal strategies, but also that piggy-backing cancer drugs for treatment of schistosomiasis is really worth considering (Dissous and Grevelding 2011).

It is interesting to note that $S$. mansoni expresses only two members of the Plk family, SmPlk1 and SmSak, and no Plk2 and Plk3 homologs, two isoforms yet present in the helminth $C$. elegans. Experiments with knock-out mice have shown that Plk1 and Plk4, but not Plk2 and Plk3, were essential for embryonic growth and viability. Plk1-/- mouse embryos did not develop beyond the eight cell stage and Plk4-/- embryos arrested at embryonic day 7.5. Plk2 and Plk3 null mice were viable, but with retarded growth, increased weight and tumor development, probably linked to the function of Plk2 and Plk3 as tumor suppressors in p53-dependent stress-response signalling (Strebhardt 2010). The absence of Plk2 and Plk3 in schistosomes would suggest that such functions are ensured by SmPlk1 or SmSak or alternatively by other components and regulating pathways that remain to be discovered. In the context of the development of novel therapies against schistosomes, a better knowledge of the catalytic domains of SmPlk1 and SmSak would also offer the possibility to target specifically such essential cell-cycle kinases in schistosomes and to design novel specific drugs for these parasite kinases.

\section{ACKNOWLEDGMENTS}

This research was supported by the Institut National de la Sante et de la Recherche Medicale, University Lille 2 in France and by the Deutsche Forschungsgemeinschaft (DFG grant GR 1549/8-1) in Germany. TL fellowship was from College Doctoral Europeen Nord Pas de Calais, University Lille 1 and the Ministere de 1'Education Nationale et de la Recherche.

\section{RESUMO}

Quinases do tipo Polo ("polo-like") são importantes reguladores da progressão do ciclo celular e da mitose. Elas constituem uma família de serina/treonina quinases que são altamente relacionadas entre si no seu domínio catalítico e contêm blocos "polo" envolvidos com interações proteína-proteína e com localização subcelular. Em mamíferos, cinco Plks (Plk 1-5) englobam diversos papéis na dinâmica do centrossomo, formação do fuso, "checkpoints" dentro da fase $\mathrm{S}$ e da transição G2/M, e na resposta aos danos do DNA. Plk1 é um regulador positivo chave da mitose, e é superexpresso em vários tipos de câncer. Plk4 é um membro divergente da família Plk, com funções essenciais na duplicação do centríolo. Deleção homozigótica de Plk1 ou Plk4 em camundongos é letal em embriões. Dois membros da família Plk, SmPlk1 e SmSak, homólogos a Plk1 e Plk4, respectivamente, estão presentes no parasita platelmíntico Schistosoma mansoni. Análises estruturais e funcionais de SmPlk1 demonstraram uma função conservada na regulação da transição G2/M do ciclo celular em ovócitos de Xenopus. A droga anticâncer BI2536 (o inibidor mais potente e seletivo de Plk1) inibe específicamente a atividade catalítica de SmPlk1 e induz alterações profundas nas gonadas de esquistossomos, indicando um papel de SmPlk1 na gametogênese do parasita e seu potencial como um alvo terapêutico novo contra a esquistossomose. As funções de SmSak na regulação do ciclo celular e no desenvolvimento das gônadas de esquistossomos estão sendo investigadas no momento.

Palavras-chave: ciclo celular, quinases do tipo Polo, reprodução, Schistosoma mansoni.

\section{REFERENCES}

Andrysik Z, Bernstein WZ, Deng L, MYer DL, Li YQ, TISCHFIELD JA, STAMBRoOK PJ AND BAHASSI EL M. 2010. The novel mouse Polo-like 5 responds to DNA damage and localizes in the nucleolus. Nucleic Acid Res 38: 2931-2943. 
Archambault V AND Glover DM. 2009. Polo-like kinases: conservation and divergence in their functions and regulation. Nat Rev Mol Cell Biol 10: 265-275.

Beckmann S, Buro C, Dissous C, Hirzmann J And Grevelding CG. 2010b. The Syk kinase SmTK4 of Schistosoma mansoni is involved in the regulation of spermatogenesis and oogenesis. PloS Pathog 6(2): e1000769.

BECKMANN S AND GREVELDING CG. 2010. Imatinib makes a fatal impact on morphology, pairing stability, and survival of adult $S$. mansoni in vitro. Int J Parasitol 40: 521-526.

BeckManN S, QuACK T, Burmeister C, Buro C, LONG T, Dissous C AND GRevelding CG. 2010a. Schistosoma mansoni: signal transduction processes during the development of the reproductive organs. Parasitology 137: 497-520.

BERRIMAN M ET AL. 2009. The genome of the blood fluke Schistosoma mansoni. Nature 460: 352-358.

Bettencourt-Dias M, Rodrigues-Martins A, CarPENTER L, Riparbelli M, LEhMANN L, GatT MK, Carmo N, Balloux F, Callaini G and Glover DM. 2005. SAK/PLK4 is required for centriole duplication and flagella development. Curr Biol 15: 2199-2207.

Chase D, Golden A, Heidecker G And Ferris DK. 2000. Caenorhabditis elegans contains a third polo-like kinase gene. DNA seq 11: 327-334.

Dissous C, Ahier A And Khayath N. 2007. Protein tyrosine kinases as new potential targets against human schistosomiasis. BioEssays 29: 1-8.

Dissous C And Grevelding CG. 2011. Piggy-backing the concept of cancer drugs for schistosomiasis treatment: a tangible perspective? Trends Parasitol 27: 59-66.

Dissous C, Khayath N, Vicogne J and Capron M. 2006. Growth factor receptors in helminth parasites: signalling and host-parasite relationships. FEBS Lett 580: 2968-2975.

Doenhoff MJ, Cioli D And Utzinger J. 2008. Praziquantel: mechanisms of action, resistance and new derivatives for schistosomiasis. Curr Opin Infect Dis 21: 659-667.

Elia AE, Cantley LC and Yaffe MB. 2003b. Proteomic screen finds pSer/pThr-binding domain localizing Plk1 to mitotic substrates. Science 299: 1228-1231.

Elia AE, Rellos P, Haire LF, Chao JW, IVins FJ, Hoepker K, Mohammad D, Cantley LC, SmerDON SJ AND YAFFE MB. 2003a. The molecular basis for phosphodependent substrate targeting and regulation of Plks by the Polo-box domain. Cell 115: 83-95.

Glover DM, Hagan IM And Tavares AA. 1998. Pololike kinases: a team that plays throughout mitosis. Genes Dev 12: 3777-3787.

HANKS SK AND QUINN AM. 1991. Protein kinase catalytic domain sequence database: identification of conserved features of primary structure and classification of family members. Methods Enzymol 200: 38-62.

JANG YJ, MA S, TERADA Y AND ERIKSON RL. 2002. Phosphorylation of threonine 210 and the role of serine 137 in the regulation of mammalian polo-like kinase. J Biol Chem 277: 44115-44120.

KING CH. 2010. Parasites and poverty: the case of schistosomiasis. Acta Trop 113: 95-104.

Kitada K, Johnson AL, Johnson LH and Sugino A. 1993. A multicopy suppressor gene of the Saccharomyces cerevisiae $\mathrm{G} 1$ cell cycle mutant gene dbf4 encodes a protein kinase and is identified as CDC5. Mol Cell Biol 13: 4445-4457.

Knobloch J, Beckmann S, Burmeister C, Quack T AND GRevelding CG. 2007. Tyrosine kinase and cooperative TGFbeta signaling in the reproductive organs of Schistosoma mansoni. Exp Parasitol 117: 318-336.

LANE HA AND NIGG EA. 1997. Cell-cycle control: Pololike kinases joint the outer circle. Trends Cell Biol 7: 63-68.

Long T, Cailliau K, Beckmann S, Browaeys E, TroLET J, GREVELding CG AND Dissous C. 2010. Schistosoma mansoni Polo-like kinase 1: A mitotic kinase with key functions in parasite reproduction. Int J Parasitol 40: 1075-1086.

LOWERY DM, LIM D AND YAFFE MB. 2005. Structure and function of polo-like kinases. Oncogene 24: 248-259.

Matthew EM, Yen TJ, Dicker DT, Dorsey JF, YANG W, NAVARAJ A AND EL-DeIRY WS. 2007. Replication stress, defective S-phase checkpoint and increased death in Plk2-deficient human cancer cells. Cell cycle 6: 25712578 .

Muhumuza S, Kitimbo G, Oryema-Lalobo M And NuWAHA F. 2009. Association between socio economic status and schistosomiasis infection in Jinja District, Uganda. Trop Med Int Health 14: 612-619.

NigG EA. 1998. Polo-like kinases: positive regulators of cell division from start to finish. Curr Opin Cell Biol 10: 776-783.

O'Connell KF, CARon C, Kopish KR, Hurd DD, KemPhues KJ, Li Y And White JG. 2001. The $C$. elegans 
$z y g-1$ gene encodes a regulator of centrosome duplication with distinct maternal and paternal roles in the embryo. Cell 105: 547-558.

OHKURA H, Hagan IM AND Glover DM. 1995. The conserved Schizosaccharomyces pombe kinase plo1, required to form a bipolar spindle, the actin ring, and septum, can drive septum formation in G1 and G2 cells. Gen Dev 9: 1059-1073.

QIAN YW, ERIKSON E AND MaLler JL. 1999. Mitotic effects of a constitutively active mutant of the Xenopus polo-like kinase Plx1. Mol Cell Biol 19: 8625-8632.

Ross AG, Bartley PB, Sleigh AC, Olds GR, Li Y, Williams GM AND MCMANUS DP. 2002. Schistosomiasis. New Eng J Med 346: 1212-1220.

SCHÖFFSKI P. 2009. Polo-like kinase (PLK) inhibitors in preclinical and early clinical development in oncology. Oncologist 14: 559-570.

Silibourne JE And Bornens M. 2010. Polo-like kinase 4: the odd one out of the family. Cell Division 5: 25.

SteEgmaier M ET AL. 2007. BI 2536, a potent and selective inhibitor of polo-like kinase 1, inhibits tumor growth in vivo. Curr Biol 17: 316-322.
StrebhardT K. 2010. Multifaceted polo-like kinases: drug targets and antitargets for cancer therapy. Nat Rev Drug Discov 9: 643-660.

Sunkel CE AND Glover DM. 1988. Polo, a mitotic mutant of Drosophila displaying abnormal spindle poles. J Cell Sci 89: 25-38.

Vicogne J, Cailliau K, Tulasne D, Browaeys E, YAN YT, FAFEUR V, Vilain JP, LEGRAND D, TROLET J AND Dissous C. 2004. Conservation of epidermal growth factor receptor function in the human parasitic helminth Schistosoma mansoni. J Biol Chem 279: 37407-37414.

Xie S, Wu H, Wang Q, Cogswell JP, Husain I, Conn C, Stambrook P, JHANWAR-UniYal M AND DAI W. 2001. Plk3 functionally links DNA damage to cell cycle arrest and apoptosis at least in part via the p53 pathway. J Biol Chem 276: 43305-43312.

Yan Y, Tulasne D, Browaeys E, Cailliau K, Khayath N, Pierce RJ, Trolet J, Fafeur V, Ben YouNES A AND Dissous C. 2007. Molecular cloning and characterisation of SmSLK, a novel Ste20-like kinase in Schistosoma mansoni. Int J Parasitol 37: 1539-1550. 